\title{
On-line monitoring of downstream bioprocesses
}

\author{
Patricia Roch and Carl-Fredrik Mandenius \\ Journal Article
}

\section{Tweet}

N.B.: When citing this work, cite the original article.

Original Publication:

Patricia Roch and Carl-Fredrik Mandenius, On-line monitoring of downstream bioprocesses, CURRENT OPINION IN CHEMICAL ENGINEERING, 2016. 14, pp.112-120.

http://dx.doi.org/10.1016/j.coche.2016.09.007

Copyright: Elsevier

$$
\text { http://www.elsevier.com/ }
$$

Postprint available at: Linköping University Electronic Press

http://urn.kb.se/resolve?urn=urn:nbn:se:liu:diva-133391

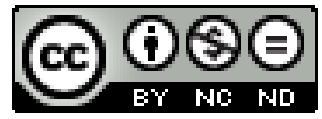




\title{
Review Article: On-line monitoring of downstream bioprocesses
}

Patricia Roch and Carl-Fredrik Mandenius

Division of Biotechnology/IFM, Linköping University, 58183 Linköping, Sweden

\begin{abstract}
Downstream bioprocessing can benefit significantly from using on-line monitoring methods for surveillance, control and optimisation. Timely information on critical operational and product quality parameters provided by on-line monitoring may contribute to high product quality, more efficient process operation and better production economy. Here, recent advances in analytical techniques and tools are critically reviewed and assessed based on their capability to meet typical needs and requirements in the biotechnology industry. Soft sensors, which merge the signals generated from online monitoring devices into mathematical models, are highlighted for accessing critical information in downstream processing.
\end{abstract}

Keywords: Bio-manufacturing; Process analytical technology (PAT); Quality by design (QbD); Software sensor; Purification 


\section{Introduction}

In industrial bio-production, process performance depends on parameters that are directly or indirectly related to the production organism, the product and the technical design and operation of the process. Parameters typically controlled in upstream processing are temperature, pressure, $\mathrm{pH}$ or dissolved oxygen. In downstream processing (DSP), however, additional parameters related to each downstream step are critical for achieving high quality and yields. This can be enhanced by incorporating on-line monitoring for acquiring critical information on process parameters and attributes $[1,2]$.

So far, on-line or at-line monitoring opportunities are sparsely discussed in downstream processing, while monitoring and control of upstream processes have attracted considerable attention [3-5]. However, monitoring and controlling single or sequential downstream processing steps could have very significant impact already in the process development phase [6] and may extensively improve the total process yield, product quality and enhance the economy of the whole process $[7,8]$

The typical downstream process in the biotechnology industry consists of several steps aiming to remove adverse product variants, and other impurities such as DNA and host cell proteins (HCPs) [9]. The final product has to be of high purity in order to meet set quality specifications and should achieve a high yield to be economically feasible. A generalised outline of a typical downstream bioprocess is shown in Figure 1. Commonly monitored and controlled process parameters (shown in white boxes) in the downstream operations seldom allow more than rough estimations of the process performance. Very rarely the concentration or composition of the target protein is measured. By introducing on-line monitoring along the downstream process, such critical information (grey boxes) can be accessed directly. This information might then serve as signals in feedback control loops for fine-tuning the operation of a process unit, for example, by facilitating fraction pooling decisions in a chromatographic step or tuning the speed of a centrifuge. Although each DSP step encounters different critical conditions, on-line or at-line monitoring may contribute to reveal information on those critical conditions directly, in a timely manner, and allowing appropriate corrective actions $[1,10,11]$.

Here, we review the potential of existing analytical techniques as on-line monitoring tools in downstream bioprocessing. The impact of on-line monitoring on product quality and production economy is elucidated as well as the ability of the on-line monitoring tools to meet regulatory demands. Recent analytical advances and new tools for monitoring in downstream processing are discussed and the prospects of soft sensors are highlighted. 
Impact of on-line monitoring on product quality, economy and regulatory compliances at industrial scale

Before implementing on-line monitoring at industrial scale it is important to carefully consider the purposes and motives of the monitoring, what kind of benefits it should accomplish and what capacities the monitoring set-up must exhibit.

Table 1 highlights these considerations by providing an overview of a variety of critical properties, factors and conditions in DSP where on-line monitoring may have substantial impact. Three areas of impact are assessed: product quality, production economy and regulatory compliance. As elucidated, on-line monitoring of quality-related criteria, such as product activity and impurities, have a consistent positive influence on production economy and regulatory demands. With more information available on the product and levels of impurities, a high product quality can be maintained in real-time within the frames of a set regulatory specification. Moreover, the real-time quality control may be reflected in lower overall manufacturing costs.

Investments in on-line monitoring equipment and costs for operation and maintenance may hamper the willingness to install plant-wide monitoring systems. However, if considering long-term gains, such as lesser personnel costs, increased productivity, process endpoint determination and decreased process downtime, investments in on-line monitoring become worthwhile.

For evaluating the impact of on-line monitoring on regulatory compliance, two kinds of aspects should be considered - those that concern the performance of the bioprocess and those that concern the monitoring technique itself. Both aspects aim at assuring the quality and safety of the final product. Regulatory demands on the bioprocess involve a thorough process documentation and the qualification of analytical techniques. Therefore, in order to implement on-line monitoring techniques design and installation qualification, as well as operational and performance qualification have to be demonstrated. This qualification will certify the capacity and reliability of the analytical techniques.

Moreover, on-line monitoring is strongly supported by the process analytical technology (PAT) initiative because it sustains flexible process control and better process understanding and facilitates quality by design $(Q b D)$ and risk assessment. By incorporating qualified on-line monitoring techniques at manufacturing scale the product quality will be ensured even if certain process parameters vary and regulatory demands will be fulfilled. 
In on-line monitoring of downstream processes a variety of process analytical information is desired. Table 2 provides a list of such information, here referred to as critical quality attributes (CQAs). The table presents assessments how these CQAs are related to typical analytical performance parameters (precision, sensitivity, response time and reproducibility). Two common categories of bioprocesses are compared: the downstream processing of proteins intracellularly produced in microbial systems (e.g. insulin, alkaline phosphatase, human granulocyte colony-stimulatory factor), and of proteins extracellularly produced in mammalian cell systems (e.g. glycoproteins or monoclonal antibodies). The assessments are based on either the authors' experiences, other expert opinions or information in literature.

When monitoring an intracellular protein produced in a microbial system the priorities tend to shift. Monitoring of cell disruption and inclusion bodies might become highly important as well as precursors, cleaved forms, aggregates and different isoforms of the product. However, impurities such as HCPs and DNA are as important as in DSP of extracellular proteins. Furthermore, endotoxins are a concern in the DSP of intracellularly produced proteins.

\section{Meeting on-line monitoring requirements with existing analytical techniques}

The ideal on-line monitoring technique should fulfil certain requirements, such as high sensitivity, fast response time, high accuracy and robustness. Moreover, it should cover a wide dynamic range, a low limit of detection, have minor recalibration needs and comply with GMP. In reality, one must find a compromise between these requirements and the information a monitoring tool can provide. Table 3 lists established techniques that rather easily can be adopted for on-line or at-line use. The table presents assessments of their biological relevance, response time, implementation complexity and price-levels.

Some of the techniques, for example low-cost sensors for temperature, pressure and optical density, provide very little information on the actual state of the biological product, but are often necessary for controlling the operation of DSP units. Techniques such as conventional high performance liquid chromatography (HPLC) are well established quality control tools although with the drawback of long response times [12].

Techniques useful to monitor the product or product variants are spectroscopic techniques as well as nuclear magnetic resonance, mass spectrometry, and surface plasmon resonance (SPR). 
There might be some reluctance in industry to implement on-line applications due to the cost efforts. For example, a spectroscopic technique requires a relatively long time to generate a robust model covering a wide dynamic range. However, once a model is established the analyte can be predicted on-line within seconds, facilitating step dependent fast decision processes and therefore improving the product quality and yield.

Defining acceptable monitoring requirements might help to identify suitable analytical techniques for the DSP steps. If the product should be monitored on-line, a less sensitive method could suffice and if a lower concentrated impurity should be monitored a longer response time might be acceptable.

\section{Recent advances in downstream process monitoring}

Demonstrations of on-line downstream monitoring is sparsely reported and, to our knowledge, very seldom used in industrial practice. Below, we summarise a few recent advances that show high potential for further on-line use.

\section{Ultraviolet spectrometry}

A few advancements of ultraviolet (UV) spectrometry for monitoring of chromatographic separation have been presented recently. For example, Kamga et al. [13] successfully quantified a target protein in a mixture of three proteins (albumin, $\beta$-lactoglobulin, immunoglobulin $\mathrm{G}$ ) using multi-wavelength UV spectrometry (250-320 nm) with multivariate data analysis (MVDA). The MVDA method used, multivariate curve resolution alternating least square (MCR-ALS) algorithm, could resolve the spectra of the proteins in the sample mixture, although the pure protein spectra overlapped. Partial least square (PLS) regression was applied to generate an accurate prediction model. Even though the study was performed off-line it indicated promising applicability of MCR-ALS in real-time multi-wavelength UV-monitoring.

A similar approach was taken by Brestrich et al. who applied UV spectroscopy (240-300 nm) with MVDA in-line at the chromatography outlet [14]. The method was applied to predict monoclonal antibody (mAb) concentration, as well as mAb aggregates and fragments in the eluent of a cation exchange column; an interesting possibility for monitoring product variants on-line [15].

The above studies [13-15] demonstrate the potential of UV spectroscopy supported by multivariate models as feasible on-line monitoring approaches for further industrial practice. PLS-based models 
could resolve the spectra of protein mixtures and quantify proteins when eluting from a chromatographic column even in undefined matrices.

\section{Fluorescence spectroscopy in chromatography}

Fluorescence spectroscopy might be even more selective than UV spectroscopy. Rathore et al. [16] have demonstrated the separation of correctly and misfolded proteins. They used tryptophan fluorescence spectroscopy to analyse the effluent of a hydrophobic interaction chromatography column. Due to the high sensitivity of fluorescence spectroscopy better pooling of the factions was possible. The reported substantial increase in product purity illustrates the potential advantage of applying fluorescence spectroscopic monitoring. However, a disadvantage was a relatively long analysis time and the required dilution of high concentrations. Furthermore, it was also noticed that this approach loses its effectiveness when the sample purity is too high (80-100\%). Consequently, implementing fluorescence spectroscopy on-line at the column outlet could also be an interesting approach to monitor correctly and misfolded target protein.

\section{Fourier transform mid-infrared spectroscopy in DSP}

A broader approach was taken by Capito et al. [17] by applying Fourier transform mid-infrared (FT-MIR) spectroscopy and PLS regression to monitor $\mathrm{mAb}, \mathrm{HCP}$ and $\mathrm{mAb}$ aggregates at-line in several DSP units. Samples of all unit operations were used which increased the model robustness. Applying FT-MIR to quantify $\mathrm{mAb}$ is a very promising method, especially because the sensitivity could be further increased. However, FT-MIR was not sensitive enough to monitor HCP or mAb aggregates but might be applied in DSP steps that are known to cause mAb aggregate formation.

All the above-mentioned combinations of spectroscopic techniques with MVDA are sensitive enough for monitoring of target proteins or impurities at higher concentrations. A severe shortcoming however, is their limited sensitivity at lower concentrations. This might be a critical issue when impurities have to be monitored for decisions on product release according to regulatory specifications.

\section{Other useful techniques}

Examples of recent advances in analytics useful for on-line monitoring in filtration and concentration downstream steps are optical density probes [12]. Furthermore, A ligand-based biosensor was applied to monitor at-line a mAb fragment throughout the entire DSP (harvest, centrifugation, resuspension, homogenization, filtration, chromatography) and resulted in yield improvements by identifying inefficient DSP units [18]. 
Moreover, SPR [19] is a monitoring tool which has seldom been utilised for process monitoring. Mandenius et al. [20] applied SPR to monitor hemagglutinin from human influenza virus in the effluent of a chromatographic column. 6'-sialyllactose-ovalbumin conjugate severed as ligand and showed sufficient stability and reproducibility. The sensitivity of SPR was demonstrated by Chavane et al. [21] who quantified correctly folded mAb in upstream processing at-line. SPR offers the possibility to monitor product variants and could also be considered to quantify leaked ligands from affinity chromatography [22].

Other promising techniques are electronic tongue $[23,24]$, NMR [25] and light scattering $[26,27]$ which might also be considered when implementing on-line monitoring downstream.

\section{New tools and approaches in downstream process monitoring}

In addition to the above mentioned analytical techniques there are some emerging tools and approaches with promising capabilities or properties for on-line monitoring applications.

\section{Monolithic separation materials}

One such opportunity is the use of monolithic separation materials. Monolithic separation materials consist of single-piece cylinders of highly cross-linked, porous polymers with a well-defined channel distribution [28]. This is in contrast to media consisting of cross-linked beads as commonly used in packed-bed columns. The sponge-like structure of monoliths enables the column to withstand much higher pressure and thereby allowing higher flow rates. Analytical monolithic columns (e.g. $\mathrm{CIM}^{\circledR}, \mathrm{BIA}$ Separations, www.biaseparations.com) can be operated at flow rates up to 30 column volumes/min with excellent separation performance. This is significantly faster than achieved with bead-based columns and leads to significantly reduced analysis time.

For example, Merhar et al. [29] demonstrated the separation of proteins using a $14 \mathrm{~s}$ linear gradient. Moreover, the immobilization of the monolithic polymer with antibodies [30] or peptides [31] was shown. Tscheliessnig and Jungbauer [32] reported a very sensitive, fast and reproducible quantification method of IgG by adopting a Protein A monolithic disk ( $\mathrm{CIM}^{\circledR}$ Protein A HLD disk from BIA Separations).

\section{Flow injection analysis}

Flow injection analysis (FIA) is a well-established methodology for automation of chemical and biochemical assays for a wide range of analytical applications [33]. Basically, the sample is injected into 
a flowing carrier stream followed by dilution, mixing with reagents, or other treatments before the detection. The variety of detection methods (e.g. electrochemical methods, photometry, mass spectrometry) demonstrates the flexibility of FIA. By applying microfluidic designs, sequential operation, automation and control, FIA provides a versatile platform technology capable of adapting to a number of assays for rapid process analysis [34-36].

These advantages were exploited by Kumar et al. [37] in a continuous flow-ELISA for monitoring of IgG. Their FIA system (VersAFlo) used a two-step immunoassay with a Protein A column. Samples, antibody conjugates and substrates were injected consecutively and detected optically.

FIA enables adoption of techniques which originally are not designed for on-line use. FIA offers multianalyte determination and therefore may be considered for DSP monitoring of e.g. HCP, endotoxins or the target product.

\section{Soft sensors}

A soft sensor is a combination of one or more measurement devices with a mathematical model. The hardware devices generate signals that are processed by a software model which then delivers new information [4]. The most common application of soft sensors is the estimation of variables which cannot be measured on-line, based on relatively easily accessible on-line data. The estimated variables are often critical quality attributes related to product quality [8].

Soft sensors can incorporate mechanistic and data-driven models [38]. Mechanistic models rely on physical and chemical principles that describe the process. Data-driven models are based on historical data which are processed by predictive methods, such as principal component regression (PCR) or PLS regression.

The application of soft sensors in downstream processing could be performed by different strategies. Several hardware sensors could, for example, be installed at the inlet and outlet of a chromatographic unit to estimate critical parameters as depicted in Figure 2. The column load could be monitored to control that the column is operated at its optimal binding capacity by e.g. UV/VIS spectroscopy (sensor A). The target protein, its glycosylation forms and product aggregates could be monitored at the column outlet by e.g. UV/VIS or multi-fluorescence spectroscopy (sensor B) and by FIA or SPR in a bypass flow (sensor $\mathrm{C}$ ).

Another monitoring strategy would be to incorporate the same sensor in each DSP step to monitor one specific variable throughout the whole DSP train. The soft sensor information from one DSP unit 
could be used to fine-tune the next one. Or the on-line data collected during upstream processing could be used in downstream processing to predict its critical operation points [39].

Soft sensors aim to simplify processes and to increase process understanding. On-line process monitoring by soft sensors facilitates the acquirement of critical process variables which enables feedback control, process automation and provides a tool for ensuring that the process is in a defined control space. By that, soft sensors comply with the PAT objectives and QbD principles. Thus, soft sensors enhance product quality, process reliability and have positive impact on production economy $[8,40]$.

\section{Conclusion}

On-line monitoring offers great potential to optimize and control downstream processing. When applied, on-line monitoring allows to obtain desired critical information in a timely manner for taking appropriate corrective actions. Each DSP unit encounters various critical conditions and requires specific critical information, depending on the purification strategy. On-line monitoring of the whole DSP train provides the opportunity to predict critical process conditions and parameters for the operation of the subsequent DSP unit. Also, important process knowledge can be incorporate to fine-tune the entire downstream process.

Correct identification of critical quality attributes and critical process parameters is of utmost importance for the choice of monitoring tools. If skilfully applied, the effect of on-line monitoring on production economy and the ability to meet regulatory demands may be substantial. We argue that despite high initial investment costs in analytical equipment the implementation of on-line monitoring into the downstream process is worth the costs and efforts due to the potentials of increasing productivity and product quality, shortening processing time and improving compliance with regulatory demands on production of drugs, food and biopharmaceuticals.

Several monitoring techniques and tools have potential to meet industrial requirements in downstream processing as on-line or at-line applications. To explore this potential would provide biotechnology industry with new opportunities to reach excellence in bio-manufacturing. 


\section{Acknowledgement}

The authors are grateful for financial support from the EU-Horizon 2020 Marie Curie ITN project BIORAPID (no. 643056) and Linköping University. 


\section{References}

1. Flickinger MC: Downstream Industrial Biotechnology: Recovery and Purification. John Wiley \& Sons Inc.; 2013.

2. Flickinger MC: Upstream Industrial Biotechnology. Equipment, Process Design, Sensing, Control, and cGMP Operations. John Wiley \& Sons Inc.; 2013.

3. Pais DA, Carrondo MJ, Alves PM, Teixeira AP: Towards real-time monitoring of therapeutic protein quality in mammalian cell processes. Curr Opin Biotechnol 2014, 30:161-167.

4. Mandenius CF, Gustavsson R: Mini-review: soft sensors as means for PAT in the manufacture of bio-therapeutics. J Chem Technol Biotechnol 2015, 90:215-227.

5. Carrondo MJT, Alves PM, Carinhas N, Glassey J, Hesse F, Merten O-W, Micheletti M, Noll T, Oliveira $\mathrm{R}$, Reichl $\mathrm{U}$, et al.: How can measurement, monitoring, modeling and control advance cell culture in industrial biotechnology? Biotechnol J 2012, 7:1522-1529.

6. Lacki KM: High throughput process development in biomanufacturing. Curr Opin Chem Eng 2014, 6:25-32.

7. Mandenius CF, Titchener-Hooker N: Measurement, Monitoring, Modelling and Control of Bioprocesses. Springer; 2013.

8. Luttmann R, Bracewell DG, Cornelissen G, Gernaey KV, Glassey J, Hass VC, Kaiser C, Preusse C, Striedner G, Mandenius CF: Soft sensors in bioprocessing: A status report and recommendations. Biotechnol J 2012, 7:1040-1048.

9. Hogwood CE, Bracewell DG, Smales CM: Measurement and control of host cell proteins (HCPs) in CHO cell bioprocesses. Curr Opin Biotechnol 2014, 30:153-160.

10. Soetaert W, Vandamme EJ: Industrial Biotechnology: Sustainable Growth and Economic Success. Wiley-VCH; 2010.

11. Stanke M, Hitzmann B: Automatic Control of Bioprocesses. In Measurement, Monitoring, Modelling and Control of Bioprocesses. Edited by Mandenius CF, Titchener-Hooker N. Springer; 2013:35-63.

12. Rathore AS, Kapoor G: Application of process analytical technology for downstream purification of biotherapeutics. J Chem Technol Biotechnol 2015, 90:228-236.

13. Kamga M-H, Lee HW, Liu J, Yoon S: Quantification of protein mixture in chromatographic separation using multi-wavelength UV spectra. Biotechnol Prog 2013, 29:664-671.

14. Brestrich N, Briskot T, Osberghaus A, Hubbuch J: A tool for selective inline quantification of coeluting proteins in chromatography using spectral analysis and partial least squares regression. Biotechnol Bioeng 2014, 111:1365-1373.

15. Brestrich N, Sanden A, Kraft A, McCann K, Bertolini J, Hubbuch J: Advances in inline quantification of co-eluting proteins in chromatography: Process-data-based model calibration and application towards real-life separation issues. Biotechnol Bioeng 2015, 112:1406-1416.

16. Rathore AS, Li X, Bartkowski W, Sharma A, Lu Y: Case Study and Application of Process Analytical Technology (PAT) towards Bioprocessing: Use of Tryptophan Fluorescence as At-line Tool for Making Pooling Decisions for Process Chromatography. Biotechnol Prog 2009, 25:1433-1439.

17. Capito F, Skudas R, Kolmar H, Hunzinger C: At-line mid infrared spectroscopy for monitoring downstream processing unit operations. Process Biochem 2015, 50:997-1005.

18. Bracewell DG, Brown RA, Hoare M: Addressing a whole bioprocess in real-time using an optical biosensor-formation, recovery and purification of antibody fragments from a recombinant E-coli host. Bioprocess Biosyst Eng 2004, 26:271-282.

19. Mattiasson B, Teeparuksapun K, Hedström M: Immunochemical binding assays for detection and quantification of trace impurities in biotechnological production. Trends Biotechnol 2010, 28:20-27.

20. Mandenius CF, Wang R, Alden A, Bergstrom G, Thebault S, Lutsch C, Ohlson S: Monitoring of influenza virus hemagglutinin in process samples using weak affinity ligands and surface plasmon resonance. Anal Chim Acta 2008, 623:66-75.

21. Chavane N, Jacquemart R, Hoemann CD, Jolicoeur M, De Crescenzo G: At-line quantification of bioactive antibody in bioreactor by surface plasmon resonance using epitope detection. Anal Biochem 2008, 378:158-165. 
22. Thillaivinayagalingam P, Newcombe AR, O'Donovan K, Francis R, Keshavarz-Moore E: Detection and quantification of affinity ligand leaching and specific antibody fragment concentration within chromatographic fractions using surface plasmon resonance. Biotechnol Appl Biochem 2007, 48:179-188.

23. Vlasov $Y$, Legin $A$, Rudnitskaya A: Electronic tongues and their analytical application. Anal Bioanal Chem 2002, 373:136-146.

24. Esbensen K, Kirsanov D, Legin A, Rudnitskaya A, Mortensen J, Pedersen J, Vognsen L, MakarychevMikhailov $S$, Vlasov Y: Fermentation monitoring using multisensor systems: Feasibility study of the electronic tongue. Anal Bioanal Chem 2004, 378:391-395.

25. Kreyenschulte $D$, Paciok E, Regestein L, Bluemich B, Buechs J: Online monitoring of fermentation processes via non-invasive low-field NMR. Biotechnol Bioeng 2015, 112:1810-1821.

26. Ahrer K, Buchacher A, lberer G, Jungbauer A: Detection of aggregate formation during production of human immunoglobulin $\mathrm{G}$ by means of light scattering. J Chromatogr $A$ 2004, 1043:41-46.

27. Ahrer K, Buchacher A, Iberer G, Josic D, Jungbauer A: Analysis of aggregates of human immunoglobulin $\mathrm{G}$ using size-exclusion chromatography, static and dynamic light scattering. J Chromatogr A 2003, 1009:89-96.

28. Svec F, Huber CG: Monolithic materials: Promises, challenges, achievements. Anal Chem 2006, 78:2101-2107.

29. Merhar M, Podgornik A, Barut M, Jaksa S, Zigon M, Strancar A: High performance reversed-phase liquid chromatography using novel CIM RP-SDVB monolithic supports. J Liq Chrom \& Rel Technol 2001, 24:2429-2443.

30. Brne P, Lim YP, Podgornik A, Barut M, Pihlar B, Strancar A: Development and characterization of methacrylate-based hydrazide monoliths for oriented immobilization of antibodies. I Chromatogr A 2009, 1216:2658-2663.

31. Neff $S$, Jungbauer A: Monolith peptide affinity chromatography for quantification of immunoglobulin M. J Chromatogr A 2011, 1218:2374-2380.

32. Tscheliessnig A, Jungbauer A: High-performance monolith affinity chromatography for fast quantitation of immunoglobulin G. J Chromatogr A 2009, 1216:2676-2682.

33. Kolev SD: Theoretical Basis of Flow Injection Analysis. In Comprehensive Analytical Chemistry. Edited by Kolev SD, Mckelvie ID. Elsevier; 2008:47-79.

34. Ranger CB: FLOW-INJECTION ANALYSIS - PRINCIPLES TECHNIQUES APPLICATIONS DESIGN. Anal Chem 1981, 53:20-32.

35. Ruzicka J, Hansen EH: Flow injection analyses: Part I. A new concept of fast continuous-flow analysis. Anal Chim Acta 1975, 78:145-157.

36. Schmid RD, Kunnecke W: Flow-Injection Analysis (FIA) Based On Enzymes Or AntibodiesApplications In The Life Sciences. J Biotechnol 1990, 14:3-31.

37. Kumar MA, Mazlomi MA, Hedström M, Mattiasson B: Versatile automated continuous flow system (VersAFlo) for bioanalysis and bioprocess control. Sensor Actuat B-Chem 2012, 161:855-861.

38. Kadlec P, Gabrys B, Strandt S: Data-driven Soft Sensors in the process industry. Comput Chem Eng 2009, 33:795-814.

39. Velayudhan A: Overview of integrated models for bioprocess engineering. Curr Opin Chem Eng 2014, 6:83-89.

40. Kourti $\mathrm{T}$ : The process analytical technology initiative and multivariate process analysis, monitoring and control. Anal Bioanal Chem 2006, 384:1043-1048.

41. Sonnleitner B: Instrumentation of biotechnological processes. Adv Biochem Eng Biotechnol 2000, 66:1-64.

42. Sonnleitner B: Automated measurement and monitoring of bioprocesses: key elements of the M(3)C strategy. Adv Biochem Eng Biotechnol 2013, 132:1-33.

43. Liu J, Mazumdar D, Lu Y: A simple and sensitive "dipstick" test in serum based on lateral flow separation of aptamer-linked nanostructures. Angew Chem Int Ed 2006, 45:7955-7959.

44. Rathore AS, Yu M, Yeboah S, Sharma A: Case study and application of process analytical technology (PAT) towards bioprocessing: use of on-line high-performance liquid 
chromatography (HPLC) for making real-time pooling decisions for process chromatography. Biotechnol Bioeng 2008, 100:306-316.

45. Teeparuksapun K, Hedström M, Kanatharana P, Thavarungkul P, Mattiasson B: Capacitive immunosensor for the detection of host cell proteins. J Biotechnol 2012, 157:207-213.

46. Luchner M, Gutmann R, Bayer K, Dunkl J, Hansel A, Herbig J, Singer W, Strobl F, Winkler K, Striedner G: Implementation of proton transfer reaction-mass spectrometry (PTR-MS) for advanced bioprocess monitoring. Biotechnol Bioeng 2012, 109:3059-3069.

47. De Vos Petersen C, Beck HC, Lauritsen FR: On-Line Monitoring of Important Organoleptic MethylBranched Aldehydes during Batch Fermentation of Starter Culture Staphylococcus xylosus Reveal New Insight into Their Production in a Model Fermentation. Biotechnol Bioeng 2004, 85:298-305.

48. Teixeira AP, Portugal CAM, Carinhas N, Dias JML, Crespo JP, Alves PM, Carrondo MJT, Oliveira R: In situ 2D fluorometry and chemometric monitoring of mammalian cell cultures. Biotechnol Bioeng 2009, 102:1098-1106.

49. Odman $\mathrm{P}$, Johansen $\mathrm{CL}$, Olsson L, Gernaey KV, Lantz AE: On-line estimation of biomass, glucose and ethanol in Saccharomyces cerevisiae cultivations using in-situ multi-wavelength fluorescence and software sensors. J Biotechnol 2009, 144:102-112.

50. Elshereef $\mathrm{R}$, Budman $\mathrm{H}$, Moresoli $\mathrm{C}$, Legge RL: Monitoring the fractionation of a whey protein isolate during dead-end membrane filtration using fluorescence and chemometric methods. Biotechnol Prog 2010, 26:168-178.

51. Bakeev KA: Process Analytical Technology: Spectroscopic Tools and Implementation Strategies for the Chemical and Pharmaceutical Industries: Second Edition. John Wiley \& Sons Inc.; 2010.

52. Noui L, Hill J, Keay PJ, Wang RY, Smith T, Yeung K, Habib G, Hoare M: Development of a high resolution UV spectrophotometer for at-line monitoring of bioprocesses. Chem Eng Process 2002, 41:107-114.

53. Hansen SK, Jamali B, Hubbuch J: Selective high throughput protein quantification based on UV absorption spectra. Biotechnol Bioeng 2013, 110:448-460.

54. Scarff M, Arnold SA, Harvey LM, McNeil B: Near Infrared Spectroscopy for bioprocess monitoring and control: Current status and future trends. Crit Rev Biotechnol 2006, 26:17-39.

55. Klimkiewicz A, Mortensen PP, Zachariassen CB, van den Berg FWJ: Monitoring an enzyme purification process using on-line and in-line NIR measurements. Chemom Intell Lab Syst 2014, 132:30-38.

56. Capito F, Skudas R, Kolmar H, Stanislawski B: Host cell protein quantification by fourier transform mid infrared spectroscopy (FT-MIR). Biotechnol Bioeng 2013, 110:252-259.

57. Oh SK, Yoo SJ, Jeong DH, Lee JM: Real-time estimation of glucose concentration in algae cultivation system using Raman spectroscopy. Bioresour Technol 2013, 142:131-137.

58. Brewster VL, Ashton L, Goodacre R: Monitoring the Glycosylation Status of Proteins Using Raman Spectroscopy. Anal Chem 2011, 83:6074-6081.

59. Ohlson S, Jungar C, Strandh M, Mandenius CF: Continuous weak-affinity immunosensing. Trends Biotechnol 2000, 18:49-52.

60. Tahkoniemi H, Helmja K, Menert A, Kaljurand M: Fermentation reactor coupled with capillary electrophoresis for on-line bioprocess monitoring. J Pharm Biomed Anal 2006, 41:1585-1591.

61. Zhao R, Natarajan A, Srienc F: A flow injection flow cytometry system for on-line monitoring of bioreactors. Biotechnol Bioeng 1999, 62:609-617.

62. Goetz J, Gross D, Koehler P: On-line observation of dough fermentation by magnetic resonance imaging and volumetric measurements. Eur Food Res Technol 2003, 217:504-511.

63. Beni V, Nilsson D, Arven P, Norberg P, Gustafsson G, Turner APF: Printed electrochemical instruments for biosensors. ECS J Solid State Sc 2015, 4:3001-3005.

64. Joshi V, Shivach T, Yadav N, Rathore AS: Circular dichroism spectroscopy as a tool for monitoring aggregation in monoclonal antibody therapeutics. Anal Chem 2014, 86:11606-11613. 


\section{FIGURE CAPTIONS}

\section{Figure 1:}

On-line monitoring of DSP steps can facilitate process decisions. Commonly monitored and controlled process parameters (white boxes) of the DSP steps are highlighted as well as the critical information desired (grey boxes). By applying on-line monitoring techniques those information can be directly provided to adjust the control parameters and to optimize each DSP step.

Note: In this example DSP homogenization is chosen as recovery; filtration and centrifugation as clarification; chromatography as purification; ultrafiltration and size exclusion chromatography as concentration/polishing step.

\section{Figure 2:}

Soft sensor consisting of multiple sensor signals applied to monitor a chromatographic step. Sensor A monitors the chromatographic inlet. Sensor B and C monitor the outlet. 
Table 1 The potential impact of monitoring on critical properties, factors and conditions in downstream processing

\begin{tabular}{|c|c|c|c|c|}
\hline Critical properties, factors and conditions & Purpose/ motivation & $\begin{array}{l}\text { Product } \\
\text { quality }\end{array}$ & $\begin{array}{l}\text { Production } \\
\text { economy }\end{array}$ & $\begin{array}{l}\text { Regulatory } \\
\text { compliance }\end{array}$ \\
\hline \multicolumn{5}{|l|}{ Product related properties } \\
\hline Product activity & Immediate information on product activity during DSP & $\lambda$ & $\lambda$ & $\lambda$ \\
\hline Product variants & Evaluation and separation of different product variants & $\lambda$ & $\pi$ & $\lambda$ \\
\hline Impurities & Assurance of sufficient removal of impurities (HCP, DNA) & $\lambda$ & $\lambda$ & $\lambda$ \\
\hline Contaminants & Detection of possible fungal, microbial, yeast bioburden & $\lambda$ & $\lambda$ & $\lambda$ \\
\hline $\begin{array}{l}\text { USP media components \& introduced } \\
\text { chemicals, resin leakage }\end{array}$ & $\begin{array}{l}\text { Assurance of sufficient removal of USP media components and } \\
\text { introduced chemicals }\end{array}$ & $\lambda$ & $\pi$ & $\lambda$ \\
\hline \multicolumn{5}{|l|}{ Economic factors } \\
\hline Investment costs of instrumentation & - & - & $y$ & - \\
\hline Operational and maintenance costs & - & - & $y$ & - \\
\hline Training costs of personnel & - & - & $y$ & - \\
\hline Productivity & Productivity improvement based on monitoring & - & $\lambda$ & - \\
\hline Direct batch release after formulation & Batch release after final DSP step, no storage & - & $\lambda$ & $\pi$ \\
\hline Process endpoint monitoring & Facilitation to determine endpoint of each DSP step & $\lambda$ & $\pi$ & $\lambda$ \\
\hline Life time of instrument & Usage for a long period of time & - & $\lambda$ & $\pi$ \\
\hline Monitoring of batch to batch variations & $\begin{array}{l}\text { Determination of batch variations and comparison to previous results } \\
\text { (batch trajectory) }\end{array}$ & $\pi$ & $\pi$ & $\lambda$ \\
\hline \multicolumn{5}{|l|}{ Conditions by regulatory demands } \\
\hline Online monitoring and process control & $\begin{array}{l}\text { Possibility to fine-tune each DSP step in a timely manner and take } \\
\text { corrective actions }\end{array}$ & $\lambda$ & $\pi$ & $\lambda$ \\
\hline Robustness of monitoring system & Adoption to changing process environment & $\lambda$ & $\pi$ & $\pi$ \\
\hline Identification of critical quality attributes & Increase process understanding and impact of CQAs in DSP steps & $\lambda$ & $\lambda$ & $\lambda$ \\
\hline Process automation & Improve process efficiency & - & $\pi$ & $\lambda$ \\
\hline Risk assessment & Evaluations of risks and risk-based product development & $\lambda$ & $\lambda$ & $\lambda$ \\
\hline Fulfilment of final product specifications & Ensuring quality criteria of each batch & $\lambda$ & $\pi$ & $\lambda$ \\
\hline
\end{tabular}

Note: $\lambda$ indicates a positive impact, a negative impact is indicated by $\searrow$ and - shows no influence. 

Table 2 Assessment of impacts of on-line monitoring properties on critical quality attributes in downstream processes of intracellular and extracellular produced products

\begin{tabular}{|c|c|c|c|c|c|c|c|c|}
\hline Critical quality attributes & Respective production & Precision & Reproducibility & Simplicity & Sensitivity & Response time & Importance & Respective DSP step of interest \\
\hline \multirow[b]{2}{*}{ Measure product } & Intra- and extracellular & ++ & ++ & ++ & ++ & ++ & +++ & Purification, Concentration, Polishing \\
\hline & $\begin{array}{l}\text { Intracellular/ } \\
\text { inclusion bodies }\end{array}$ & ++ & ++ & ++ & +++ & +++ & +++ & $\begin{array}{l}\text { Recovery, Purification, Concentration, } \\
\text { Polishing }\end{array}$ \\
\hline \multicolumn{9}{|l|}{ Product related impurities } \\
\hline - Glycosylation & Extracellular & +++ & +++ & + & +++ & +++ & +++ & Purification \\
\hline \multirow{2}{*}{ - Multimers } & Extracellular & ++ & ++ & ++ & +t & ++ & ++ & Concentration, Purification \\
\hline & Intracellular & ++ & ++ & ++ & ++ & ++ & + & Concentration, Purification \\
\hline \multirow{2}{*}{ - Aggregates } & Extracellular & ++ & ++ & ++ & +++ & +++ & +++ & Recovery, Concentration, virus inactivation \\
\hline & Intracellular & +++ & ++ & ++ & +++ & +++ & +++ & Recovery, Concentration \\
\hline - Fragments & Extracellular & ++ & ++ & ++ & +++ & +++ & +++ & Purification, Concentration, Polishing \\
\hline $\begin{array}{ll}- & \text { Precursors/ } \\
& \text { cleaved forms }\end{array}$ & Intracellular & +++ & ++ & ++ & +++ & ++ & +++ & Purification \\
\hline - Clipped forms & Extracellular & +++ & ++ & ++ & +++ & ++ & ++ & Purification \\
\hline - Deamidation & Intra- and extracellular & ++ & ++ & ++ & +++ & ++ & ++ & Purification \\
\hline \multirow{2}{*}{ - Oxidized form } & Extracellular & +++ & +++ & ++ & +++ & +++ & ++ & Purification \\
\hline & Intracellular & +t+ & ++ & ++ & ++ & ++ & ++ & Purification \\
\hline $\begin{array}{ll}\text { - } & \text { Different } \\
\text { isoforms }\end{array}$ & Intracellular & +++ & +++ & ++ & +++ & +++ & +++ & Purification \\
\hline \multicolumn{9}{|l|}{ Process related impurities } \\
\hline Measure HCP & Intra- and extracellular & ++ & ++ & ++ & +++ & ++ & ++ & Purification, Concentration, Polishing \\
\hline Measure DNA & Intra- and extracellular & ++ & ++ & ++ & +++ & ++ & ++ & Clarification, Purification \\
\hline Measure endotoxins & Intracellular & ++ & ++ & ++ & +++ & ++ & ++ & Purification, Concentration, Polishing \\
\hline \multirow[b]{2}{*}{ Measure resin leakage } & Protein A (extracellular) & +++ & ++ & ++ & +++ & ++ & ++ & Purification, Concentration, Polishing \\
\hline & $\begin{array}{l}\text { Other resins (intra- and } \\
\text { extracellular) }\end{array}$ & +++ & ++ & ++ & +++ & ++ & + & Purification, Concentration, Polishing \\
\hline $\begin{array}{l}\text { Measure introduced } \\
\text { chemicals/enzymes }\end{array}$ & Intra- and extracellular & ++ & ++ & ++ & +++ & + & ++ & Concentration, Polishing \\
\hline Measure proteases & Intra- and extracellular & ++ & ++ & ++ & ++ & +++ & ++ & Recovery \\
\hline Measure bioburden & Intra- and extracellular & +++ & ++ & ++ & +++ & + & ++ & Purification, Concentration, Polishing \\
\hline \multirow{2}{*}{ USP media components } & Extracellular & ++ & ++ & ++ & ++ & ++ & ++ & Recovery, Clarification \\
\hline & Intracellular & t+ & ++ & ++ & ++ & ++ & + & Recovery, Clarification \\
\hline \multicolumn{9}{|c|}{ Evaluate equipment performance } \\
\hline - Column recovery & Intra- and extracellular & + & +++ & +++ & ++ & ++ & + & Purification \\
\hline $\begin{array}{l}\text { - Binding capacity } \\
\text { over time }\end{array}$ & Intra- and extracellular & + & +++ & +++ & ++ & ++ & + & Purification \\
\hline $\begin{array}{l}\text { - Membrane } \\
\text { integrity }\end{array}$ & Intra- and extracellular & ++ & ++ & +++ & ++ & +++ & + & Purification, Clarification, Concentration \\
\hline
\end{tabular}

Note: The intracellular protein (orange) is produced in a microbial production system and the extracellular protein (grey) is produced in a mammalian cell culture. Relevance for both production systems is indicated in white. 
Table 3 Assessment of capacity of existing analytical techniques to monitor downstream processing

\begin{tabular}{|c|c|c|c|c|c|c|c|c|c|}
\hline Techniques & $\begin{array}{l}\text { Biological } \\
\text { relevance }\end{array}$ & Sensitivity & Selectivity & $\begin{array}{l}\text { Response } \\
\text { time }\end{array}$ & Precision & Reproducibility & $\begin{array}{l}\text { Readiness for } \\
\text { Implementation }\end{array}$ & $\begin{array}{l}\text { Price } \\
\text { level }\end{array}$ & Reference \\
\hline Temperature and pressure sensors & $\bullet$ & $\bullet \bullet \bullet$ & $\bullet$ & $\bullet \bullet \bullet$ & $\bullet \bullet \bullet$ & $\bullet \bullet \bullet$ & $\bullet$ & $\mid$ & [41] \\
\hline pH sensor & $\bullet$ & $\bullet \bullet \bullet$ & $\bullet$ & $\bullet \bullet \bullet$ & $\bullet \bullet \bullet$ & $\bullet \bullet$ & $\bullet$ & & [41] \\
\hline Optical density & $\bullet$ & $\bullet \bullet$ & $\bullet$ & $\bullet \bullet \bullet$ & $\bullet \bullet$ & $\bullet \bullet$ & $\bullet$ & & {$[42]$} \\
\hline Mass flowmeters & $\bullet$ & $\bullet$ & $\bullet$ & $\bullet \bullet \bullet$ & $\bullet \bullet$ & $\bullet \bullet$ & $\bullet$ & & {$[42]$} \\
\hline Dipsticks for antigens & $\bullet \bullet \bullet$ & $\bullet$ & $\bullet \bullet$ & $\bullet \bullet$ & $\bullet$ & $\bullet \bullet$ & $\bullet$ & & {$[43]$} \\
\hline Flow injection analysis & $\bullet \bullet$ & $\bullet \bullet$ & $\bullet \bullet$ & $\bullet \bullet$ & $\bullet \bullet$ & $\bullet \bullet$ & $\bullet \bullet$ & & [35] \\
\hline HPLC online & $\bullet \bullet$ & $\bullet \bullet$ & $\bullet \bullet$ & $\bullet \bullet$ & $\bullet \bullet \bullet$ & $\bullet \bullet$ & $\bullet \bullet \bullet$ & & {$[44]$} \\
\hline Capacitive immunosensors & $\bullet \bullet$ & $\bullet \bullet \bullet$ & $\bullet \bullet \bullet$ & $\bullet \bullet$ & $\bullet \bullet$ & $\bullet \bullet$ & $\bullet \bullet \bullet$ & & {$[19 \bullet, 45]$} \\
\hline Advanced mass spectrometry & $\bullet \bullet \bullet$ & $\bullet \bullet \bullet$ & $\bullet \bullet \bullet$ & $\bullet \bullet$ & $\bullet \bullet$ & $\bullet \bullet$ & $\bullet \bullet$ & & {$[46,47]$} \\
\hline Multi fluorescence spectroscopy & $\bullet$ & $\bullet \bullet \bullet$ & $\bullet \bullet$ & $\bullet \bullet \bullet$ & $\bullet \bullet \bullet$ & $\bullet \bullet$ & $\bullet \bullet$ & & [48-51] \\
\hline UV/VIS spectroscopy & $\bullet \bullet$ & $\bullet \bullet$ & $\bullet \bullet \bullet$ & $\bullet \bullet \bullet$ & $\bullet \bullet \bullet$ & $\bullet \bullet$ & $\bullet \bullet$ & & {$[13 \cdot, 51-53]$} \\
\hline Near-infrared spectroscopy & $\bullet \bullet$ & $\bullet \bullet$ & $\bullet \bullet$ & $\bullet \bullet \bullet$ & $\bullet \bullet \bullet$ & $\bullet \bullet$ & $\bullet \bullet$ & & {$[51,54,55]$} \\
\hline Mid-infrared spectroscopy & $\bullet \bullet$ & $\bullet \bullet$ & $\bullet \bullet \bullet$ & $\bullet \bullet \bullet$ & $\bullet \bullet \bullet$ & $\bullet \bullet$ & $\bullet \bullet$ & & {$[17 \cdot, 51,56]$} \\
\hline Raman spectroscopy & $\bullet \bullet \bullet$ & $\bullet \bullet$ & $\bullet$ & $\bullet \bullet \bullet$ & $\bullet \bullet \bullet$ & $\bullet \bullet$ & $\bullet \bullet$ & & {$[51,57,58]$} \\
\hline Surface Plasmon Resonance & $\bullet \bullet \bullet$ & $\bullet \bullet \bullet$ & $\bullet \bullet \bullet$ & $\bullet \bullet$ & $\bullet \bullet$ & $\bullet$ & $\bullet \bullet \bullet$ & & {$[19 \cdot 59]$} \\
\hline Capillary electrophoresis online & $\bullet \bullet$ & $\bullet \bullet$ & $\bullet \bullet$ & $\bullet \bullet$ & $\bullet \bullet$ & & $\bullet \bullet$ & & {$[60]$} \\
\hline Flow cytometry online & $\bullet \bullet$ & $\bullet \bullet$ & $\bullet \bullet$ & $\bullet \bullet$ & $\bullet \bullet$ & $\bullet \bullet$ & $\bullet \bullet$ & & {$[42,61]$} \\
\hline NMR online & $\bullet \bullet \bullet$ & $\bullet \bullet$ & $\bullet \bullet \bullet$ & $\bullet$ & $\bullet \bullet \bullet$ & $\bullet \bullet$ & $\bullet \bullet$ & & {$[25,62]$} \\
\hline Off-line biosensors & $\bullet \bullet \bullet$ & $\bullet \bullet \bullet$ & $\bullet \bullet \bullet$ & $\bullet \bullet$ & $\bullet \bullet$ & $\bullet \bullet$ & $\bullet \bullet \bullet$ & & [63] \\
\hline Circular Dichroism & $\bullet \bullet \bullet$ & $\bullet \bullet \bullet$ & $\bullet \bullet \bullet$ & $\bullet \bullet$ & $\bullet \bullet$ & $\bullet \bullet$ & $\bullet \bullet$ & & {$[64]$} \\
\hline Light scattering & $\bullet \bullet$ & $\bullet \bullet \bullet$ & $\bullet$ & $\bullet \bullet$ & $\bullet \bullet$ & $\bullet \bullet$ & $\bullet \bullet$ & & {$[26,27]$} \\
\hline
\end{tabular}




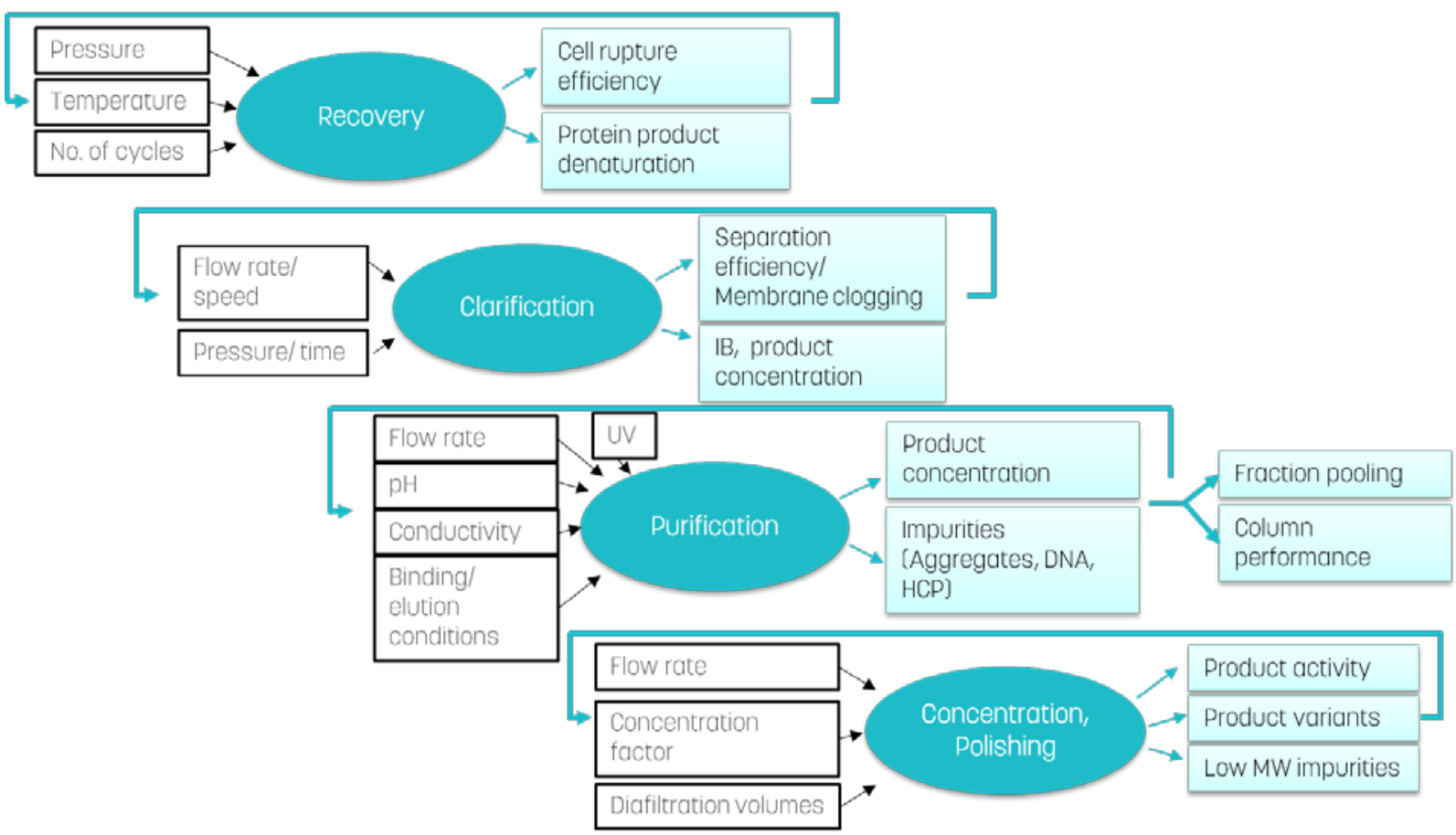

Figure 1 On-line monitoring of DSP steps can facilitate process decisions. Commonly monitored and controlled process parameters (white boxes) of the DSP steps are highlighted as well as the critical information desired (blue boxes). By applying on-line monitoring techniques those information can be directly provided to adjust the control parameters and to optimize each DSP step.

Note: In this example DSP homogenization is chosen as recovery; filtration and centrifugation as clarification; chromatography as purification; ultrafiltration and size exclusion chromatography as concentration/polishing step. 


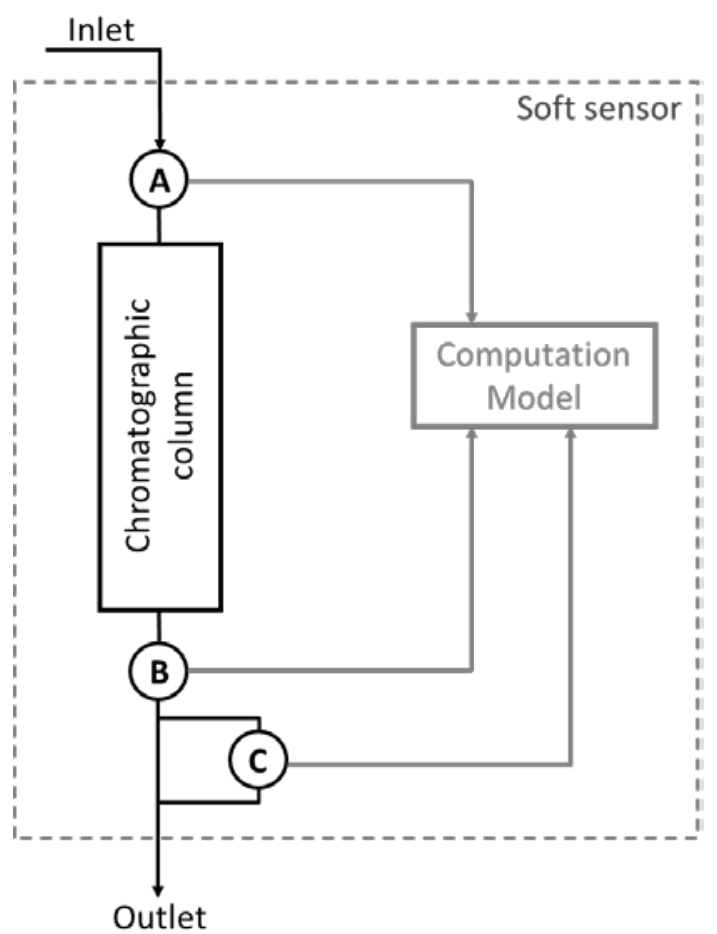

Figure 2 Soft sensor consisting of multiple sensor signals applied to monitor a chromatographic step. Sensor A monitors the chromatographic inlet. Sensor $B$ and $C$ monitor the outlet. 